\title{
HAMLET E O DISCURSO DO OUTRO (A)*
}

\author{
Manfred Rommel Pontes Viana Mourão ${ }^{1}$
}

Maria Cristina de Távora Sparano

\section{Resumo}

Tomando as ideias propostas por M. Foucault e J. Lacan, trataremos a noção de discurso como elaboração linguística da relação ao Outro com vistas a entender a nomeação no decorrer da História e como ela contribui para a psicanálise e a crítica literária. Proporemos uma análise da tragédia shakespeariana Hamlet, trazendo para o debate a perspectiva dos dois autores supracitados acerca da problemática do discurso do Outro, verificado tanto na personagem que dá nome a peça, Hamlet, quanto em Ophelia. Assim, nossa exposição trará a tona a ressignificação do desejo do Outro a partir da articulação dos discursos das personagens da peça fundamental do dramaturgo inglês.

Palavras-chave: Discurso do Outro. Hamlet. Ressignificação.

\begin{abstract}
Turning the ideas proposed by M. Foucault and J. Lacan, we will treat the notion of discourse as linguistic elaboration of the relationship with the other in order to understand the nomination throughout History and how it contributes to psychoanalysis and the literary criticism. We propose an analysis of Shakespearean tragedy Hamlet, bringing to the debate the prospects of two aforementioned authors about the issue of discourse of the Other, verified as both in the character that gives its name to play, Hamlet, as in Ophelia. Thus, our exposure will bring forth the resignification of desire the Other according to the articulation of the discourses the English playwright keystone's characters.
\end{abstract}

Keywords: Discourse of the Other. Hamlet. Ressignification.

\footnotetext{
${ }^{1}$ Mestrando do Programa de Pós-Graduação em Letras, Estudos Literários da UFPI. Endereço eletrônico: manfred_rm@hotmail.com.

${ }^{2}$ Psicanalista e Professora Dra. do Programa de Pós-Graduação em Letras, Estudos literários: metodologia da psicanálise e conceitos fundamentais de psicanálise, da Universidade Federal do Piauí (UFPI) Endereço eletrônico: cris-sparano@ufpi.edu.br.

*A- na simbologia lacaniana: o Outro da Linguagem
} 


\section{INTRODUÇÃO}

Em As palavras e as coisas, Foucault (2007) nos oferece um percurso acerca da nomeação no mundo moderno e suas oposições no tocante a outros períodos. A nomeação que encontramos a partir do século XVII em diante - no qual o nosso Hamlet se insinua partirá ao princípio agora baseado nas leis de similitude e diferença. Enquanto o mundo clássico lidava com a representação, a partir da modernidade o assunto será tratado pela relação do sentido e da significação. A linguagem, assim, passará de casos particulares de representação (clássicos) para os de significação (modernos e contemporâneos). A interdependência da linguagem se desfaz, a escrita se suspende, desaparece a camada onde se entrecruzam o visto e o lido, o visível e o enunciável: "As coisas e as palavras vão separar-se. O olho será destinado a ver e somente a ver; o ouvido somente a ouvir. O discurso terá realmente por tarefa dizer o que é, mas não será nada mais que o que ele diz." (FOUCAULT, 2007, p. 59)

Em termos de tragédia, na modernidade, ela aparece como uma forma de representação que reclama o direito do indivíduo a seu destino, de suas ações frente a outrem. Em outras palavras, ela reclama o valor do herói a partir de sua identidade e sua diferença, tal como os nomes exigiram para si. Nesse liame, a partir das análises aqui apresentadas, sob a perspectiva das teorias psicanalíticas que abarcam o complexo de Édipo, na linha que Freud e Lacan estabeleceram, mostraremos como se conduz a significação do desejo nas personagens da peça Hamlet, de W. Shakespeare.

Diante do exposto, a leitura da obra de que falamos procura enfatizar as questões sempre concernentes ao discurso, do qual a psicanálise busca contrastar por um fio de "associações" ou "superposições", já que falamos de uma estrutura simbólica a ser desvendada. (BELLEMIN-NÖEL, 1983, p. 81). Assim, buscaremos ressaltar a natureza do discurso na obra literária moderna, situando 1 a composição dessa peça num tempo marcado por uma nova visão sobre a linguagem como assinala Foucault e 2 qual a relação destes dois no nível do complexo de Édipo. 


\section{O TEMPO DO DISCURSO DO OUTRO}

Seria incoerente achar que o tempo seria algo irrelevante para a análise literária, mas Lacan pensou assim. Contudo, para esta análise, trataremos de pensar o herói num sentido histórico, o que primeiro se fará pela oposição do protagonista antigo ao moderno.

Desde já, encontramos distinções quanto à apresentação do herói no mundo moderno, o que podemos visualizar pelo personagem do Quixote. O personagem de Cervantes se põe entre a identidade e a diferença, seu ser é linguagem, mas ele quer ser semelhante a esses signos que ele carrega, e faz isso porque ele quer prová-los, pois os signos (visíveis) já não são semelhantes a seres (visíveis). Assim, ele quer transformar a narrativa em uma sequência de signos sem conteúdo, cujo intuito é modificar a realidade em signo, ou seja, provar que os signos da linguagem não são iguais às próprias coisas. A obra de Cervantes desenha o negativo do mundo no Renascimento, o personagem do escritor espanhol passa a ser agora o intermediário entre a palavra e a coisa, o falado e o pensado. (SKÁRMETA, 2005, p. 107)

James Wood (2012, p. 119) nos lembra quando o personagem manda seu fiel escudeiro Sancho procurar Dulcineia ele fica sozinho por um período mais ou menos prolongado. Nessa oportunidade, a personagem, que agora está só, “[ [...] não pensa no sentido que hoje se entende pelo termo. Ele fala alto, fala sozinho." O romance tem origem no teatro, e a caracterização no romance tem origem no momento em que o solilóquio se interioriza, caracterizando os personagens como nas peças de Shakespeare. Logo, quando Hamlet divaga ele fala, quando ele fala ele divaga; a literatura moderna transforma a arte da caracterização porque transforma quem vê o personagem.

Desse modo, as identidades e as diferenças no livro de Cervantes (o herói e o autor, o signo Mesmo e o Outro) mostram como se desdenham as diferenças e as similitudes pela fala do Quixote. Ele confunde a razão com a sua insanidade e duvida do que é tido como absoluto em seus sentidos, ele toma algo pelo que não é e as pessoas pelo que não são, ignora o amigo e reconhece o estranho, é o "louco" do século XVI, que "[...] só é o Diferente na medida em que não conhece a Diferença” (FOUCAULT, 2007, p. 67), 
ele vê em tudo semelhanças e sinais, "[...] todos os signos para ele se assemelham e todas as semelhanças valem como signos" (FOUCAULT, 2007, p. 67).

A poesia e a loucura passam a ser as marcas de uma nova experiência da linguagem, de um saber que separa os seres e a linguagem limitando seu poder. Desse modo, o louco, por homossemantismo, reúne todos os signos e os preenche com uma semelhança que não cessa de proliferar e o poeta faz o sentido inverso, ou seja, sustenta o papel alegórico que busca em outra linguagem, sem palavras nem discursos, da semelhança: "O poeta faz chegar a similitude até os signos que a dizem, o louco carrega todos os signos com uma semelhança que acaba por apagá-los.” (FOUCAULT, 2007, p. 68)

É, então, nessa situação "limite", entre o marginal e o arcaico da linguagem que no mundo ocidental se abre um espaço para o pensamento das palavras e das coisas, cuja questão não são mais as similitudes, mas as identidades e as diferenças. O problema, contudo, de se falar do nome é uma questão que Foucault reporta a um nível de significação que passa por alguns processos que se baseiam na teoria da proposição e singularmente do verbo, mais precisamente do verbo ser, pois este verbo nomeia, ele idealiza a representação. Assim, nomear é (pelo verbo ser) representar. Em outras palavras, para Foucault a palavra designa; ela, em sua natureza, é nome: nome próprio que aponta para “'[...] tal representação e mais nenhuma". Desse modo, que a uniformidade dos nomes pululam de uma taxonomia para outra, sendo necessária a criação de tantos nomes quantas coisas a nomear: "Mas então cada nome seria tão fortemente a única representação que ele designa, que não se poderia sequer formular a menor atribuição; e a linguagem recairia abaixo de si mesma". (FOUCAULT, 2007, p. 135)

A proposta de Foucault é que tudo já foi nome, nome próprio em si. Assim, na dinâmica geral da linguagem, o nome aparece como o ponto para onde converge toda a língua, protegida por suas convenções, regras, história, entrando numa relação com a verdade pela qual será julgada. Aí se funda toda a experiência clássica da linguagem. O nome é o que organiza todo o discurso clássico, escrever ou falar não é exprimir-se, não é jogar com a linguagem, é “[...] encaminhar-se em direção ao ato soberano de nomeação, é ir, através da linguagem, até o lugar onde as coisas e as palavras se ligam em sua essência comum, e que permite-lhes dar um nome.” (FOUCAULT, 2007, p. 166) 
Toda literatura clássica se funda nesse movimento, de levar os nomes ao seu sentido absoluto - utilizando de uma estratégia retórica - para, com este ato de movimento à palavra, violentar a sua origem e legitimar o termo adequado e absoluto para nomear as coisas. Nesse cerne, a literatura foi a forma pela qual se pôde romper com esse "ser" da linguagem clássica, cuja função era representar: a literatura moderna detém e libera esse ser para si mesmo.

Nessa moldura da acepção clássica da linguagem e da nova perspectiva que se criara nos séculos XVII e XVIII, podemos definir a experiência da linguagem como uma forma de determinar sob que condições a linguagem podia tornar-se um objeto epistemológico e em que limites ela se desdobraria. Longe de definir qualquer denominador comum, a linguagem procurava opiniões agora pelas quais se poderiam confrontar, onde a periferia da linguagem sempre era mais relevante do que o seu centro e cuja estrutura “[...] mostra de que modo a linguagem se imbrica com o que lhe é exterior e indispensável.” (FOUCAULT, 2007, p. 168)

Nesse sentido desenvolvido por Foucault, há símiles a serem debatidos acerca das ideias psicanalíticas, pois, tal como percebemos na psicanálise, o nome é caracterizado por uma função simbólica para se pensar o discurso. Ele nunca representa as coisas em si, mas aquilo que é anterior ao mesmo, ou seja, ele está atrelado a todo um processo de mudanças sociais e históricas que acompanham essa linguagem e tem uma iniciação no sujeito em sua tenra idade, a partir da relação simbólica entre a figura objeto de seu desejo (mãe) e de sua lei (pai). Em outras palavras, queremos dizer que não há como se perceber a natureza do desejo e da castração no sujeito senão pelo discurso, haja vista a proposição lacaniana de que o inconsciente é articulado pela linguagem. Essas questões estão atreladas a noção de origem que os discursos explicitam, e desde Freud aparece embasado pela figura do Pai.

Freud falava do Pai como substância real do complexo de Édipo, o que, em termos do patriarcado europeu do início do século XX, seria explicitado pela "metáfora paterna". Lacan (1999), retomando a ideia de Freud, dirá que este é apenas uma instância simbólica, sendo os discursos humanos guiados por noções que figuram de acordo com o tempo e o lugar em que os sujeitos se utilizam dessa linguagem. Os discursos se constituem, na verdade, a partir da relação com o Outro que adquire para o sujeito uma característica 
castradora, a lei. Nesse âmbito, o complexo de Édipo não é puramente pessoal, mas uma experiência do sujeito no âmbito social da "Lei": "The prohibition, in other words, is merely represented in the individual figure of the child actual's father; it is essentially a Symbolic relation and as such works through the father as 'name', as metaphor for the Law itself." (BRITTON, 1995, p. 203)

Tal ponto de vista é fundamental dentro do que nos propusemos a analisar nesse trabalho, pois o discurso do Outro passa a ser não mais uma unidade fixa e absoluta como poderíamos pensar a representação dos discursos para o mundo antigo ou do Pai para Freud, mas antes seria uma caracterização simbólica e mutável da linguagem em detrimento do desaparecimento daquela que é anterior e necessária para si. É nesse cerne que a perspectiva de Foucault se assemelha à de Lacan, pois ambos pensam suas teorias a partir da relação dos discursos, como um conflito de identidades e diferenças, semelhanças e dessemelhanças. Em outras palavras, tanto Lacan quanto Foucault acreditam que o significado de um discurso tal como ele é não existe se não pensarmos o que é exterior à ele ou se articule com ele. De qualquer modo, se fazem críticas a certas noções que subjazem as teorias dos dois autores abordados que talvez se complementem aqui.

Nessa linha de raciocínio pensar a peça fundamental de Shakespeare, como nos propusemos a fazer aqui, é articulá-la, tendo como pressuposto a noção histórica do discurso como elemento construído ao que lhe é exterior a partir do Renascimento de Shakespeare e as noções lacanianas de discurso do Outro, analisadas a seguir.

\section{HAMLET: O DISCURSO DO OUTRO}

A ação trágica no mundo moderno é circundada pelo ideal de justiça e liberdade tal como na tragédia antiga, mas antes a justiça nesta se centra no interior do personagem, sendo complexa e pouco satisfatória, pois “[...] é a personagem em si, e desse modo o destino individual, que são enfatizados acima da substância ética que a personagem representa." (WILLIANS, 2002, p. 56) Na tragédia moderna, o conflito que se desenvolve no interior do próprio herói, mas antes de ser pura e simples ação do "espírito", em sua 
pretensa individualidade e mesmidade, ela abarca um exterior que leva ao conflito por meio de um jogo dialético de forças individuais conflitantes.

Esse conflito que a tragédia expõe pode ser pensado em questões de linguagem, já que desde o início do século XVII as palavras não mais representavam aquilo que lhes eram próprias, mas sua individualidade se configurava a partir de um princípio onde a significação interna dos termos agora precisaria entrar em conflito com os demais termos para ganhar significação. Assim, a tragédia do dramaturgo e poeta inglês W. Shakespeare, Hamlet, fonte dos mais diversos estudos da literatura ocidental, nos propõe uma leitura infinda acerca de tal ponto, dentro do que pensamos sobre a interioridade humana e suas relações a partir do discurso, reiterando o que os estudos acerca da obra nos oferece em Freud e Lacan.

Segundo Freud (1986) um acontecimento real na vida de Shakespeare o impulsionou a representá-lo em Hamlet. A questão da hesitação em Hamlet de vingar o assassinato de seu pai, perpetrado pelo irmão deste, se constitui para Freud como passível de receber uma explicação, a partir da teoria psicanalítica. Freud considera que a hesitação de Hamlet quanto a esta tarefa - ao ser contraposta a sua ausência de escrúpulos, ao mandar seus cortesãos à morte, ao matar Polônio, e, ao lançar-se a um embate mortal com Laertes só poderia ser explicada pela "[...] obscura lembrança de que ele próprio havia contemplado praticar a mesma ação contra o pai, por paixão pela mãe" (FREUD, 1986, p. 273).

Para Lacan, o estudo de Hamlet nos leva para dois campos: o do desejo e o do discurso. Lacan nos oferecerá tal parecer ao ressaltar o seu intuito de "[...] montrer dans Hamlet la tragédie du désir, du désir humain” (LACAN, 1984, p. 7). Pensar o homem no sentido em que nos propusemos é, inevitavelmente, pensar o Mesmo através do Outro, no entanto isso só é possível por meio do discurso.

No tratamento da peça de Shakespeare, Lacan partirá do Complexo de Édipo para estabelecer as relações desenvolvidas no decorrer da trama, pelo impasse de Hamlet com o pai e a mãe. É nessa linha de raciocínio que Lacan trará o personagem Hamlet para o centro da experiência analítica, pois ele é analisado como instância de uma configuração discursiva, ou simbólica, no nível da tripartite lacaniana. 
Assim, Hamlet é um sujeito atravessado pela linguagem $(\$)$ e que se inventaria na peça a partir de um princípio de relação e diferença com o Outro $(A){ }^{3}$ Sob a égide do estruturalismo, Lacan manifesta a análise de Hamlet a partir do princípio da perspectiva edipiana e a metodologia de análise saussuriana. Em sua discussão da articulação da peça, que questiona diversos objetos como o autor, os atores, os críticos e o texto, Lacan privilegia a leitura da peça em sua estrutura interna como chave para apreendê-la, através da ordem de uma ilusão, a qual produz na peça um efeito "fantomático": "de l'ordre de ce que vous representé, d'un certain angle et d'un certain point, mon petit miroir concave, nécessite toute une machinerie.” (LACAN, 1984, p. 14)

Contudo, esta ilusão não vocifera o fato de ali conter um vazio. Hamlet, segundo Lacan, é a peça onde herói e poeta se distinguem, pois eles só podem estar aí por seu discurso e apenas por ele que somos capazes de perceber quem são. No entanto, não se pode dizer que a comunicação do inconsciente possa se conceber de forma "presentificada" (LACAN, 1984), mas sim por meio da articulação do discurso dramático. Desse modo, não há inconsciente antes do discurso dramático, a presença do texto de Hamlet diz o que e quem é Hamlet: "Le héros [...] est strictement identique aux mots du texte." (LACAN, 1984, p. 14)

Este valor do discurso dramático que trata Lacan está ligado ao efeito da peça, e nos toca precisamente o efeito mais profundo: o plano do inconsciente. Contudo, isso não é em razão da presença de alguma coisa que realmente suporta frente a nós um inconsciente, como o inconsciente do poeta, mas o inconsciente do próprio príncipe dinamarquês, que dá valor àquilo que se estrutura ao nível do Édipo. Trata-se da peça que nos coloca o problema da subjetividade humana e do desejo.

Não é o ponto por trás de Hamlet que nos interessa segundo Lacan, é a composição da própria peça. Essa composição conduziu a um elevado grau que faz dela alguma coisa que se distingue de todos os pré-Hamlet que pudemos descobrir por uma articulação, pois se há o drama de Shakespeare por trás da peça isso é secundário em relação ao que compõe a estrutura. É essa estrutura que responde ao efeito Hamlet.

${ }^{3}$ Simbologia lacaniana. Tinha por objetivo sistematizar em gráficos e esquemas a natureza do inconsciente dos sujeitos e suas características mais fundamentais. Alguns dos símbolos são constantes, os dois acima são paradigmáticos em toda a obra de Lacan. 
Na perspectiva do inconsciente que se busca na estrutura da peça em si, a função deste se define a partir do discurso do Outro: "l'inconscient que se présentifie là sous la forme du discours de l'Autre, qui est un discours parfeitement composé." (LACAN, 1984, p. 17) O herói só está aí presente por esse discurso, da mesma forma que o poeta; por outro lado, este está "morto", pois ele se configura apenas como um simulacro do texto. O que evidenciamos aqui é a leitura e sua interpretação.

Hamlet constitui a nossa relação com o inconsciente, é isso o que nossa relação com o significante quer dizer e somos nós que fornecemos o material disso. Esse aspecto é dado comumente no registro analítico como articulação e compreensão daquilo que é Hamlet, como alguma coisa que parece ir nesse sentido, uma oposição (LACAN, 1984, p. 17 - 18). E muito embora seja seguro dizer que Hamlet é a tragédia da interioridade, ela não nos oferece em toda a sua estrutura elementos que se limitem apenas a isso, antes suas características apontam para um universo inter e intrasubjetivo, onde o desejo é dominado pelo mundo em que o Outro se encontra.

Este Outro, como nos assegura Lacan (1984), nasce da figura materna, sujeito primordial da demanda. Não obstante, o pai de Hamlet se apresenta como o fantasma, não na acepção do insólito personagem simplesmente, mas na forma de motivação contra Claudius, na predisposição do príncipe frente a sua dimensão intersocial. Assim, o príncipe convive entre o seu desejo (motivado por Gertrudes) e a sua Lei (motivada por seu pai). O mistério de Hamlet se encontra entre os dois, e nessa faca de dois gumes é o desejo que anseia ser atravessado. Nessa oscilação o sujeito se caracteriza. Mas só consegue isso através do discurso, o discurso do Outro.

No Ato III, Cena IV, o episódio pós-play scene, temos essa imagem célebre da relação pai-mãe-filho cuja análise merece ser ressaltada. A sequência de martírio em que Hamlet leva a sua mãe é interseccionada pelo fantasma, e assombrado agora por algo além de sua alma apenas, o pai, lhe traz a tona o que deve ser seu fito: “O, step between her and her fighting soul" (SHAKESPEARE, 2007, p. 696). Hamlet se abstém de suas atitudes e agora se volta à purificação do Outro. Na oportunidade ele vai adjurar pateticamente sua mãe de tomar consciência do ponto em que ela se encontra, a de uma vida vergonhosa e 
incestuosa, da qual quer consertar, ensinando-a a portar-se melhor, começando por não dormir mais com Claudius.

Eis o problema que se apresenta: porque Hamlet não age? Para Lacan (1984) é seu desejo que parece suspenso por aquilo que ele não pode querer: o desejo para com a mãe. Este é recalcado, cuja causa torna o herói indeciso, não sabendo avançar na direção da ação que lhe é encomendada por seu pai, a vingança contra Claudius, (o Phallus). Antes disso, se dá a lembrança do desejo infantil pela mãe, e ele é cúmplice do possuidor.

A questão de Hamlet, contudo, é que para estancar sua própria culpabilidade, ele deve procurar o culpado fora do verdadeiro culpado. O que Lacan atenta para a conecção do Phallus, onde o termo é substituído pelo reinado: "The body is with the king, but the king is not with the body" (apud BRITTON, 1995, p. 210). Aí o pai se encontra, pois o pai volta do além sob a forma de um fantasma para lhe ordenar este ato de punição; com sua autoridade diz ser vítima, agora despossuído não somente do objeto de seu amor, mas de sua potência, de seu trono,de seu corpo.

A ação de Hamlet não é desinteressada, como nos assegura Lacan (1984, p. 20), ela é "kantiennement motivée". Assim, Hamlet não pode cumprir o seu ato, pois aí está alguma coisa que podemos dizer, mas que é "quase" acessível diante da investigação psicanalítica. Lacan segue o texto, ou seja, aquilo que Hamlet enfrenta, pois é um desejo que deve ser observado, que não é “[...] son désir pour sa mére, c’est le désir de sa mére.” (LACAN, 1984, p. 20) Poderíamos chamar isso, para o caso, de "le désir naturel d'Hamlet" (LACAN, 1984, p. 19). De fato, se ele não pôde sentir, separado dessa mãe, é importante para ele que seja fixado à esta. Portanto, esse desejo é "natural".

Ernest Jones (apud LACAN, 1984, p. 19 - 20) escreve sobre Hamlet, defendendo ele a dimensão do recalque e da censura, seguindo a tendência de dar a essa censura uma origem social. Diz ele, que as coisas que evidentemente são as mais censuradas pela organização social, são os desejos mais naturais. Isto poderia nos conduzir um pouco mais adiante no cerne da percepção sensível das necessidades sociológicas que não são nem um pouco exauridas para explicar esse tipo de interdição, de onde surge a dimensão do inconsciente, tal como Freud nos demonstrará pelo mito original, onde a realidade psíquica 
necessita da realidade histórica para sustentá-la (FREUD, 1996, p. 162) e, com isso, explicar os princípios do recalque.

Logo, Hamlet expressa a tendência imperativa que é para ele duplamente comandada pela autoridade do pai e o amor que ele lhe dedica; e a de querer defender sua mãe e de guardá-la para si, que devem fazê-lo ir no sentido de matar Claudius. O que distingue Hamlet de Édipo, é que Hamlet, através do discurso, significa. No príncipe não são os deuses que delimitam o seu destino. Podemos notar isso nas suas atitudes frente a Claudius, cuja substância ética que guarda causa repugnância aos olhos do príncipe: este é um assassino e merece ser punido por seu crime. Porém, Hamlet, por conta da ausência do pai mesmo, ressignifica-o. Sabendo deste, Hamlet é privado, não agindo para com Claudius, agora desejo de sua mãe, o Phallus. Matar a este seria, portanto, cometer suicídio.

Nesse cruzamento de questões podemos chegar ao ponto advogado nesse trabalho, que toca a crítica do sujeito e sua relação discursiva com o Outro: o Pai (a Lei) e a mãe (o seu desejo natural). Pois, tal como advogamos, o príncipe só consegue explicitar a sua autoidentificação através da relação dialética de seu próprio discurso com as duas outras instâncias simbólicas, rearticulando a sua própria noção de discurso cada vez que cruza com o Outro.

\section{OPHELIA: O DISCURSO VOLTA-SE PARA SI MESMA}

Podemos examinar o problema do discurso do Outro do ângulo de uma personagem importante para a peça de Shakespeare: Ophelia. O assunto corresponde a relação da personagem com o Outro, mais precisamente com a figura de seu desejo, Polonius. Essa questão, contudo, vai além, numa perspectiva de assujeitamento, loucura e desejo, sobre a prerrogativa da existência da Lei mesma e que examinaremos a seguir.

De início, é contundente dizer que Hamlet passa a ser assujeitado por Ophelia em determinado momento da peça como uma forma de repositório de seu desejo, eis a função de Ophelia. Independente disso, Ophelia articula seu próprio desejo e Hamlet é elemento repositor para ela tanto quanto o inverso. Desse modo, o drama de Hamlet pode ser pensado do ponto de vista de Ophelia e, mesmo havendo distinções claras entre os dois, eles 
possuem certa ligação, cuja natureza é ressaltada pelas causas da tristeza de Hamlet. Aí está a ingênua sabedoria psicanalítica de Polonius: ele é triste porque não está feliz, não é feliz por causa de sua filha.

Para o caso de Hamlet, encontraremos em Ophelia alguma coisa que configura o objeto de seu amor. "I did love you once" (SHAKESPEARE, 2007, p. 680), diz Hamlet. As coisas se passam com Ophelia nesse estilo de agressão cruel e de sarcasmo. O que temos em Ophelia é uma continuação do drama de Hamlet e que segundo o próprio Lacan (1984) se caracteriza como a armadilha do príncipe, o seu objeto e a sua nova demanda. É sob a atmosfera da loucura e do suicídio de Ophelia (levado pela morte de Polonius e tendo como consequência a revolta de Laertes) que o desfecho da peça se arranja, como poderemos ver adiante.

Ophelia age sempre regulada por seu pai, portanto seu discurso é, de certa forma balizado pelo de Polonius, para ela, a Lei Mesma. Ademais, mesmo que Ophelia discorde dele, ela o obedece, pois ele é o Outro fundamental para ela identificar-se a si mesma. É daí, que do ponto de vista de Ophelia o seu desejo é articulado. Contudo, com a morte de Polonius no episódio pós-play scene se configura uma ausência do Pai e Ophelia é forçada a viver em um mundo cruel por si. Desse modo, depois da morte de Polonius, Ophelia precisa construir um discurso de si mesma, e a voz é o que expressa o seu ser, mais do que isso, ela precisa de um objeto para refletir seu próprio desejo, e essa voz possibilita o seu discurso, um discurso para o Outro.

De outro modo, Ophelia está sem o Outro, largada sem o seu desejo e sem o seu próprio ser, que agora se interioriza. Hamlet e Laertes participam também nessa nova perspectiva de Ophelia, distantes, eles não podem auxiliá-la na constituição de uma nova Lei. A loucura, portanto, significa a constituição de Ophelia por sua própria voz, e através dessa voz insana, Ophelia substitui o discurso que lhe guia pelas suas próprias palavras. Portanto, ela substituiu o seu pai para ser o seu próprio Outro.

É nesse sentido que Maurice e Hanna Charney (apud CHIN, 2011, p. 9) afirmam: “[...] her madness opens up her role [...] Madness enables her to assert her being; she is no longer enforced to keep silent and play the dutiful daughter". Como seu ser nunca foi 
verdadeiramente exibido até a morte de Polonius (o que justifica a rejeição a Hamlet), ela autoidentifica-se e o Outro fica suspenso.

Assim, Ophelia é ressignificada, de uma moça obediente e sedutora, explorada por Claudius e Polonius, para quebrar "[...] the subjection of a vehemently patriarchal society and makes public display, in her verses, of the body she has been taught to suppress" (SALKED apud CHIN, 2010, p. 10). O que em outras palavras significa dizer que ela liberta-se do atrelamento ao pai, no entanto, conduz tal libertação a um nível agora desprovido de qualquer desejo pelo Outro; sua voz, nesse sentido, é sua fonte de loucura e liberdade.

Em sua loucura, Ophelia primeiro fala de suas dores, o mundo agora está destroçado por conta da morte de Polonius. Ela é definitivamente diferente da coerente e bem comportada garota sob a tutela de seu pai, mas agora frustrada e importunada, Ophelia expressa apenas o seu próprio discurso, em palavras insanas e tristes.

Outro ponto a se ressaltar está no fato de a voz de Ophelia ser uma voz feminina; assim, demente, provocada pelo patriarcalismo dominante, não pode ser compreendida e, desse modo, é considerada louca. Em outras palavras, a voz de Ophelia é ilógica e irracional porque é uma voz alienada pelo sistema tal como ele é, o patriarcalismo hegemônico, “[...] whose language is supposed to be rational and organized. Hence, Ophelia is identified to be mad because her language is excluded and marginalized from the-Name-of-the-Father/ the patriarchal authority." (CHIN, 2007, p. 10) Em outras palavras, a autoridade é o pai, o Outro mesmo e fundamental. O Nome do Pai é uma verdade autoritária, mas ela se ressignifica e aponta para um novo sentido, pois o Outro nunca é simplesmente aquilo mesmo, mas uma instância de identidade. ${ }^{4}$

Assim, o que distingue Hamlet de Ophelia frente ao discurso do Outro é a possibilidade de ressignificação que o primeiro pode dar ao pai, exasperando por isso sua ação para com a sua mãe e a Claudius dá-lhe o Outro fundamental; esta perspectiva torna-

\footnotetext{
${ }^{4}$ O Nome do Pai não pode ser tomado tal como o Pai é proposto por Freud. Antes, para o caso em discussão, ele é o elemento fundamental para o processo de substituição e troca que inscreve um lugar normativo para o sujeito; porém, esse acesso metafórico de identidade é exatamente o lugar da proibição e da repressão, conflito de autoridade. A identificação pronunciada no Desejo do Outro é sempre uma questão de interpretação, pois ela é um encontro furtivo entre o Mesmo e o Outro.
} 
se impossível na personagem Ophelia, que terá que arcar com seu próprio interior e louco discurso.

Hamlet fica enciumado por Claudius, pois este tem nome, este é conhecido, este é real, é o rei. O pai, contudo, não passa de virtualidade, de objeto perdido, que não interessa por sua realidade, mas por sua simbologia. É nesse enfoque da morte do pai e da perda da mãe que se constitui o Édipo, e que Hamlet entra em cena para matar o pai sob a figura de Claudius, com o toque de neurose e obsessão que permeia o personagem por toda a peça.

Certamente, seria simplório dizer que o rei é o rei, e o bobo é o bobo. A questão vai além em Hamlet, em sua apuração das circunstâncias que cercam cada um dos personagens da peça, seus caráteres e suas ações. O que motiva Hamlet a ter com sua mãe, e agir como agiu, é a falta de objeto que permeia o seu desejo (LACAN, 1999). Sua obsessão se fundamenta em um dano imaginário que procura por algo que ele não precisa, a estratégia de Shakespeare, nesse sentido, é possibilitar essa leitura, onde o objeto perdido é buscado através de Ophelia.

Ele aceita tudo mas também quer controlar tudo. No entanto, no início de sua mágoa, antes mesmo do encontro com o fantasma de seu pai e o desvendar do crime que assolava o reino da Dinamarca, ou mesmo do casamento da mãe com seu tio, ele pensava em ir para Wittenberg, contudo, permanece.

É pelo Outro e no tempo dos outros que ele suspende seu crime; é no tempo de seu sogro que ele embarca para a Inglaterra; é no de Rosencrantz e Guildenstern que ele é conduzido, evidentemente a enviá-los adiante da morte, graças a um truque bastante bem sucedido. E é assim mesmo, no tempo de Ofélia também, no momento do seu suicídio, que essa tragédia vai encontrar seu termo, momento em que Hamlet, ao passar pelo túmulo sendo cavado, parece perceber que matar alguém não é difícil. (LACAN, 1984, p. 22)

Neste momento lhe anunciam algo que não parece em nada uma ocasião para matar Claudius: um torneio sobre o qual todos os detalhes foram minuciosamente e traiçoeiramente preparados, de cujo desfecho temos conhecimento. O Ato final da peça desemboca a perspectiva de que Hamlet afinal pode matar Claudius, pois ele próprio está morrendo e sua reparação parece ser consumada. Talvez ele reconheça que o desejo por sua 
mãe ou Ophelia é impossível, e Claudius, mais uma vez se caracterizando como um facínora, o revolta. Num entremeio de desejo e Lei, Hamlet pode executar a sua vingança.

O discurso do Outro nos apresenta uma posição que para a psicanálise leva em conta a natureza do patriarcado, da entidade que guia as ações do sujeito frente a Lei, que não é somente a Lei, mas a instância simbólica desta. Na ausência dessa, o sujeito fica entregue ao desejo natural, fornecido pela figura materna. O discurso apenas nomeia pela sua relação com o Outro, há pois no discurso do Outro o significado que ressalta a ética e o desejo do herói; assim, ao final da peça, em seu acting out, a identificação entra em conflito ante a iminência da morte. Nesse momento, a morte cessa o ato de significação.

\section{CONCLUSÃO}

A representação, livre de qualquer relação, é apenas apresentação. A linguagem clássica nos oferecia uma nomeação que cingia o signo, com seu ser primitivo, único e enigmático. Contudo, a significação que os signos tomaram do século XVII para os dias atuais mudou, o saber que se operou desde então, através de um movimento de semelhança e dessemelhança, gerou uma teoria da significação pela relação.

Certamente, foi a literatura que, na modernidade, retomou o ser vivo da linguagem. Nos séculos XVII e XVIII a literatura passou a se caracterizar como um contradiscurso e remeter, assim, àquele ser vivo da linguagem clássica, da representação, só que no seu sentido oposto: o da relação de signos. Hamlet aí se encontra.

$\mathrm{Na}$ cena estrutural que Foucault ressalta, Lacan segue na sua busca da significação do discurso do Outro, através do ato de ressignificação que o contato com novas instâncias simbólicas podem trazer. Lacan toma o Pai como o mediador nas novas formas de significação ante as mudanças da estrutura orquestradas diante daquele que detém a Lei. A diferença reside, basicamente, na instituição da "metáfora paterna", que para Ophelia a impede de desejar outrem senão o pai, instância maior de seu desejo, cuja morte leva esta à insanidade. Hamlet, por outro lado, explora a "metáfora paterna" no tio, que agora é ressignificado, no lugar de seu pai, percebendo nele a oportunidade de identificar-se com a Lei. 
É nesse jogo de identificação e diferença que o sujeito aparece com seu desejo, mostrando que a interdição e a Lei, para Lacan, terão dupla entrada, não permitindo divisões e que, finalmente, o sujeito surge na composição do discurso somente através da compreensão da ambivalência e do antagonismo do desejo do Outro.

Afinal, em se havendo a força diferenciadora do Outro, o processo de significação do sujeito através da linguagem e a objetivação da sociedade na Lei, como poderia o Outro desaparecer? Mesmo diante da dúvida a Lei mesma nunca se evanesce; ela muda, refaz-se, assume o papel de sua contínua ressignificação operada pelo discurso do Outro. O Pai pode ser reidentificado através do discurso do Outro, a Lei que ele guarda não.

\section{REFERÊNCIAS}

BELLEMIN-NOËL, Jean. Psicanálise e literatura. Tradução de Álvaro Lorencini e Sandra Nitrini. São Paulo: Cultrix, 1983.

BRITTON, Celia. Structuralist and post-structuralist psychoanalytic and marxist theories. In: SELDON, Raman (org.). Cambridge history of literary criticism: from Formalism to Post-structuralism (vol. 8). Cambridge: Cambridge University Press, 1995.

CHIN, Yi-Chi. Pregnant with madness: Ophelia's struggle and madness in Hamlet. In: Intergrams, Lecturer of the Language Center. Taiwan: Southern Taiwan University, 2011.

FOUCAULT, Michel. As palavras e as coisas. Tradução de Salma Tannus Muchail. ed. 9. São Paulo: Martins Fontes, 2007.

FREUD, Sigmund. A correspondência completa de Sigmund Freud para Wilhelm Fliess 1887-1904. Editado por Jeffrey Masson. Rio de Janeiro, Imago, 1986.

FREUD, Sigmund. Totem e tabu. Tradução de Vera Ribeiro. Rio de Janeiro: Imago, 1996.

LACAN, Jaques. Desire and the interpretation of desire in Hamlet. Yale: Yale French Studies, 1997.

LACAN, Jacques. Le seminaire 4. Paris: Éditions du Seuil, 1999.

LACAN, Jacques. Le désir de la mère. In: MILLER, Jacques-Alain (org.). Ornicar. Paris, 
1984.

LACAN, Jacques. L’objet Ophélie. In: MILLER, Jacques-Alain (org.). Ornicar. Paris, 1984.

SHAKESPEARE, William. Hamlet, prince of Denmark. In: The complete works of William Shakespeare. London: Wordsworth Editions, 2007.

SKÁRMETA, Antonio. El double juego de Don Quijote: desrealización de la realidad y realización de lo irreal. Estudios Públicos, n. 100, 2005.

WILLIANS, Raymond. Tragédia moderna. Tradução de Betina Bischof. São Paulo: Cosac Naify, 2002.

WOOD, James. Como funciona a ficção. Tradução de Denise Bottmann. São Paulo: Cosac Naify, 2012. 